Discussiones Mathematicae

Note

\title{
A NOTE ON TOTAL GRAPHS
}

\author{
S.F. Forouhandeh ${ }^{1}$, N. JAFARI RAD ${ }^{1}$ \\ B.H. Vaqari Motlagh ${ }^{1}$, H.P. Patil ${ }^{2}$
}

AND

\author{
R. PANDIYA RAJ ${ }^{2}$ \\ ${ }^{1}$ Department of Mathematics \\ Shahrood University of Technology \\ Shahrood, Iran \\ ${ }^{2}$ Department of Mathematics \\ Pondicherry Central University \\ Puducherry - India \\ e-mail: n.jafarirad@gmail.com \\ hpppondy@gmail.com
}

\begin{abstract}
Erratum: Identification and corrections of the existing mistakes in the paper On the total graph of Mycielski graphs, central graphs and their covering numbers, Discuss. Math. Graph Theory 33 (2013) 361-371.
\end{abstract}

Keywords: total graph, central graph, middle graph, Mycielski graph.

2010 Mathematics Subject Classification: 05C76, 05C69.

\section{Results}

In this paper, we correct the Theorems 1, 4, 8 and 11, and their corollaries of [1]. There was omitted $t(G)$, i.e., the number of triangles in $G$ or $L(G)$ in Theorem 1 of [1]. The total graph $T(G)$ contains triangles in $G, L(G)$ and in the incidence graph. All triangles are numbered in the published paper [1] beside triangles in $G$ or $L(G)$. First, we give corrected version of Theorem 1 of [1] as follows by adding the number of omitted triangles $t(G)$, and its proof is in similar lines as before. 
Theorem 1. For any $(p, q)$ graph $G$,

$$
t[T(G)]=2 t(G)+\frac{1}{2} \sum_{i=1}^{p}\left[d_{G}^{2}\left(v_{i}\right)+2 m_{i}\left(\begin{array}{c}
d_{G}\left(v_{i}\right) \\
3
\end{array}\right)\right],
$$

where $m_{i}=1$ if $d_{G}\left(v_{i}\right) \geq 3$; otherwise $m_{i}=0$.

Due to the change in the statement of Theorem 1 of [1], the remaining Theorems 4, 8, 11 and their corollaries of [1] are corrected as follows.

Corollary 2. (a) $t\left[T\left(C_{3}\right)\right]=8$ and $t\left[T\left(C_{n}\right)\right]=2 n$ if $n>3$.

(b) For $n \geq 1, t\left[T\left(K_{n}\right)\right]=\frac{1}{6}\left[\left(n^{2}-n\right)\left(n^{2}-1\right)\right]$.

Corollary 3. For $1 \leq i \leq n$ and $n \geq 2, t\left[T\left(\square_{i=1}^{n} C_{m_{i}}\right)\right]=\frac{2 M n}{3}\left(2 n^{2}+1\right)$ where $M=m_{1} m_{2} \cdots m_{n}, m_{i}>3$.

Theorem 4. Let $G$ be any $(p, q)$-graph having $t(G)$ triangles and $\delta(G) \geq 2$. Then

$$
t[T(\mu(G))]=8 t(G)+\frac{1}{2} \sum_{i=1}^{p}\left[3 d_{G}^{3}\left(v_{i}\right)+d_{g}^{2}\left(v_{i}\right)\right]+\left(\frac{18 q+5 p+p^{3}}{6}\right) .
$$

Corollary 5. For $n>3, t\left(T\left[\mu\left(C_{n}\right)\right]\right)=\left(\frac{n^{3}+107 n}{6}\right)$.

Corollary 6. For $n \geq 3, t\left(T\left[\mu\left(K_{n}\right)\right]\right)=\frac{1}{6}\left(9 n^{4}-15 n^{3}+6 n^{2}+6 n\right)$.

Theorem 7. For any $(p, q)$-graph $G$,

$$
t[M(G)]=t(G)+\frac{1}{2} \sum_{i=1}^{p}\left[d_{G}^{2}\left(v_{i}\right)+2 m_{i}\left(\begin{array}{c}
d_{G}\left(v_{i}\right) \\
3
\end{array}\right)\right]-q,
$$

where $m_{i}=1$ if $d_{G}\left(v_{i}\right) \geq 3$; otherwise $m_{i}=0$.

Corollary 8. For any $(p, q)$-graph $G$,

$$
t[M(\mu(G))]=4 t(G)+\frac{1}{2} \sum_{i=1}^{p}\left[3 d_{G}^{3}\left(v_{i}\right)+d_{G}^{2}\left(v_{i}\right)\right]+\frac{p\left(p^{2}-1\right)}{6} .
$$

Theorem 9. For any $(p, q)$-graph $G$ with $p \geq 4$,

$$
t[T(C(G))]=2 m+\frac{1}{6}\left(p^{4}-3 p^{3}+5 p^{2}-3 p+12 q\right),
$$

where $m=t(C(G))$.

Corollary 10. For $m, n \geq 3$,

$$
t\left[T\left(C\left(K_{m, n}\right)\right)\right]=t\left[T\left(K_{m+n}\right)\right]-m n(m+n-4) .
$$




\section{Acknowledgement}

The authors gratefully acknowledge the referee for his valuable suggestions.

\section{REFERENCES}

[1] H.P. Patil and R. Pandiya Raj, On the total graph of Mycielski graphs, central graphs and their covering numbers, Discuss. Math. Graph Theory 33 (2013) 361-71. doi:10.7151/dmgt.1670

Received 3 May 2014

Revised 4 July 2014

Accepted 3 September 2014 